\title{
A PROTEÇÃO DAS MARCAS NO DIREITO BRASILEIRO
}

Fabrícia Alcantara ${ }^{1}$

\section{RESUMO}

A função exercida pelas marcas, que, antigamente, limitava-se à identificação do produtor, evoluiu para uma concepção de marca que, hoje, faz referência ao produto em si. No Brasil, os titulares de marcas têm seus direitos assegurados, primeiramente, face à garantia constitucional conferida à propriedade industrial pelo art. $5^{\circ}$, inc. XXIX, da Constituição Federal, complementada pela disciplina da Lei no 9.279 de 1996, da Convenção da União de Paris para a Proteção da Propriedade Industrial (CUP) e do Acordo sobre Aspectos dos Direitos de Propriedade Intelectual Relacionados ao Comércio (TRIPS). O direito industrial brasileiro adota o sistema de exame prévio para tramitação de pedidos de marca, por meio do qual o Instituto Nacional de Propriedade Industrial examina as condições de registrabilidade cunho distintivo, novidade, veracidade e caráter lícito - antes de decidir pela concessão do registro. A propriedade da marca adquire-se pelo registro validamente concedido, mas também são assegurados direitos ao depositante que ainda não teve seu pedido apreciado, podendo desde logo zelar por sua reputação. A proteção marcária é limitada pelos princípios da territorialidade, cuja exceção é a marca notoriamente conhecida, e da especialidade, que tem por exceção a marca de alto renome.

\section{ABSTRACT}

The function exerted for the trademarks, that, in other times, was limited to identify the producer, evolved to a conception of trademark that, today, make reference to the product. In Brazil, the owners of trademarks have theirs rights assured, firstly, face to the constitutional guarantee granted to the industrial

\footnotetext{
${ }^{1}$ Advogada, formada pela Universidade Federal do Paraná e pós-graduada pela Pontifícia Universidade Católica do Paraná.
}

Revista Brasileira de Direito Internacional, Curitiba, v.4, n.4, jul./dez.2006 
property for the article $5^{\circ}, \mathrm{XXIX}$, of the Federal Constitution, complemented by the discipline of Law no 9,279 of 1996, Convention of the Union of Paris for the Protection of the Industrial Property (CUP) and Trade Related Aspects of Intellectual Property Rights (TRIPS). Brazilian Industrial Law adopts a system of previous examination for the mark register, by which the National Institute of Industrial Property examines the register conditions - distinctiveness, newness, veracity and allowed character - before deciding to grant the register. The mark's property is acquired by the valid register granted, but also there are assured rights for the applicant who still not have its application appreciated, he can to take care of the mark reputation. The trademark protection is limited by the principle of territoriality, whose exception is the mark notoriously known, and by the principle of specialty, that has for exception the mark of high reputation.

Indicadores: PROPRIEDADE INTELECTUAL - MARCAS - LEGISLAÇÃO BRASILEIRA

Keywords: INTELLECTUAL PROPERTY - TRADEMARKS - BRAZILIAN LAW

\section{INTRODUÇÃO}

A noção jurídica de marca evoluiu ao longo dos anos, em razão das mudanças na realidade da prática mercantil.

Para alguns autores, a origem das marcas remonta à Antiguidade, quando elas não apresentavam sentido comercial, mas apenas a função de indicar a propriedade dos objetos, como forma de evitar furtos. No entanto, autores como JOÃO DA GAMA CERQUEIRA ${ }^{2}$ e FRANCESCHELLI ${ }^{3}$ afirmam que o uso das marcas ocorreu somente a partir da Idade Média, período em que elas passaram a possuir funções e características mais próximas de sua configuração atual, sendo-Ihes agregado o sentido mercantil.

\footnotetext{
${ }^{2}$ CERQUEIRA, Gama. Tratado de propriedade industrial. Rio de janeiro: Forense, 1956. vol. 1, p. 342.

${ }^{3}$ FRANCESCHELLI, Remo. Trattato di diritto industriale. Milão: Giuffrè, 1973. vol. I, p.156.
}

Revista Brasileira de Direito Internacional, Curitiba, v.4, n.4, jul./dez.2006 
Vislumbra-se a origem das marcas no período medieval com base no sentido econômico e jurídico que elas passaram a ter naquela época, ao exercerem a função de indicação da corporação de ofício em que determinado artigo era fabricado, sendo, por isso, conhecidas como "marcas corporativas".

A função exercida pelas marcas não é mais a mesma. As grandes mudanças econômicas provocadas pela Revolução Industrial e pela Revolução Francesa fizeram com que o sistema das marcas corporativas desaparecesse. A função da marca, que na Idade Média se referia ao produtor, evoluiu para uma marca que, hoje, faz referência ao produto em si. ${ }^{4}$

Atualmente, não raro, além de exercer sua função distintiva de produtos ou serviços, a marca passa ainda a significar um importante valor econômico para seu titular, sendo contabilizada, inclusive, como ativo empresarial.

\section{EVOLUÇÃO DA LEGISLAÇÃO MARCÁRIA BRASILEIRA}

O Código Comercial Brasileiro, Lei n ${ }^{\circ} 556$ de 1850, não previu dentre seus dispositivos nenhuma norma específica que regulasse as marcas. Apenas em 1875, o Decreto $\mathrm{n}^{-} 2.682$ foi o primeiro diploma legal a regular a propriedade industrial no Brasil, incentivado por Rui Barbosa ao ver um de seus clientes prejudicado pela falta de lei que regulasse a contrafação de marcas. ${ }^{5}$

Após este, vários outros decretos e leis se seguiram, sendo que 0 diploma atual que regula a propriedade industrial em nosso país é a Lei no 9.279 de 1996, a qual revogou o antigo Código de Propriedade Industrial, Lei oㅡ 5.772 de 1971.

A partir de 1992, passou-se a adotar, para o tratamento das marcas no país, também as regras da Convenção da União de Paris para a Proteção da Propriedade Industrial, atualizada pela Revisão de Estocolmo de 1967. Dentre suas principais disposições, cumpre destacar o estabelecimento da

\footnotetext{
${ }^{4}$ MORO, Maitê Cecília Fabbri. Direito de marcas: abordagem das marcas notórias na Lei 9.279/1996 e nos acordos internacionais. São Paulo: Revista dos Tribunais, 2003. p. 26.

${ }^{5}$ No caso Rapé Areia Preta X Rapé Areia Parda, Rui Barbosa obteve acórdão desfavorável ao seu cliente frente à inexistência de tipificação do delito de contrafação das marcas de indústria e de comércio.
}

Revista Brasileira de Direito Internacional, Curitiba, v.4, n.4, jul./dez.2006 
independência dos registros de marcas em cada país, o direito de prioridade assegurado ao titular de pedido de marca com anterioridade de pelo menos seis meses em outro país signatário, a repressão ao uso indevido de marcas e o tratamento nacional dispensado entre os países-membros.

Outro importante instrumento referente à matéria é o Acordo sobre Aspectos dos Direitos de Propriedade Intelectual Relacionados ao Comércio (Trade Related Aspects of Intellectual Property Rights - TRIPS), que se encontra em vigor desde 1995, após ter sido incorporado ao direito interno brasileiro pelo Decreto n 1.355 de 1994.

Este acordo prevê um patamar mínimo de proteção da propriedade intelectual, não impedindo o legislador interno de estabelecer uma proteção mais abrangente aos direitos de propriedade intelectual, salvo nas hipóteses em que a excessiva proteção venha a constituir um obstáculo ao livre comércio internacional. ${ }^{6}$ Traz como princípios básicos o tratamento nacional, o princípio da nação mais favorecida, pelo qual todas as vantagens concedidas por um Estado-parte a outro devem ser estendidas a todas outras partes do acordo, e o benefício ao desenvolvimento sócio-econômico.

\section{MARCA: DEFINIÇÃO, NATUREZA JURÍDICA E CLASSIFICAÇÃO}

Segundo os ensinamentos de JOÃO DA GAMA CERQUEIRA, marca é "todo sinal distintivo aposto facultativamente aos produtos e artigos das indústrias em geral para identificá-los e diferençá-los de outros idênticos ou semelhantes de origem diversa" ${ }^{\prime 7}$. O autor considera a marca como um bem imaterial, que é protegido juridicamente em razão de seu caráter patrimonial.

CARVALHO DE MENDONÇA sugere uma definição mais precisa, atribuindo duas funções à marca: a de distinguir o produto e a de indicar a origem comercial. Afirma o autor:

\footnotetext{
${ }^{6}$ LOUREIRO, Luiz Guilherme de A. V. A lei de propriedade industrial comentada. São Paulo: Lejus, 1999. p. 34.

${ }^{7}$ CERQUEIRA, João da Gama. Tratado de propriedade industrial. Rio de janeiro: Forense, 1956. vol. 1, p. 365.
}

Revista Brasileira de Direito Internacional, Curitiba, v.4, n.4, jul./dez.2006 


\begin{abstract}
"[M]arcas consistem em sinais gráficos ou figurativos, destinados a individualizar os produtos de uma empresa industrial ou as mercadorias postas à venda em uma casa de negócio, dando a conhecer sua origem ou procedência, e atestando a atividade e o trabalho de que são resultado." ${ }^{8}$
\end{abstract}

Com relação à definição de marca, a Organização Mundial da Propriedade Intelectual (OMPI) alerta não ser possível chegar a um conceito internacional e apresenta a seguinte sugestão de definição a seus membros:

"[U]n signo visible que permite distinguir los bienes y servicios de otras empresas tratándose de un bien incorporal, cuyo principal valor reside en el prestigio y reputación que representa" $"$.

Da análise da legislação marcária brasileira resulta que o antigo Código de Propriedade Industrial Brasileiro, Lei no 5.772/71, estabelecia que a marca seria utilizada para distinguir produtos, mercadorias ou serviços de outros idênticos ou semelhantes, na classe correspondente à atividade de seu titular. No entanto, quando da elaboração da Lei no 9.279/96, o legislador optou por uma solução mais simples, prevendo no art. 122: "são suscetíveis de registro como marca os sinais distintivos visualmente perceptíveis, não compreendidos nas proibições legais".

Fixou-se então um conceito amplo de marca, utilizando-se de um critério negativo e descartando aqueles sinais que não sejam distintivos ou visualmente perceptíveis e aqueles não permitidos por lei.

O caráter da distintividade, quase unânime nas definições empreendidas por doutrinadores nacionais e estrangeiros, é condição essencial de validade da marca. Dentre as funções que a marca pode exercer na economia moderna, a mais relevante é justamente a sua função distintiva, pela qual a marca serve precipuamente para distinguir os produtos e serviços de outros idênticos ou semelhantes. Complementarmente, existem outras funções

\footnotetext{
${ }^{8}$ MENDONÇA, Carvalho de. Tratado de direito comercial brasileiro. 5. ed. Rio de Janeiro: Freitas Bastos, 1955. vol. V, parte I, p. 215.

${ }^{9}$ Extraído do endereço eletrônico www.wipo.int, em 02/07/2006.
}

Revista Brasileira de Direito Internacional, Curitiba, v.4, n.4, jul./dez.2006 
não essenciais da marca, como a função de indicação de origem, a função de indicação de qualidade, a função econômica e a função publicitária. ${ }^{10}$

A marca é considerada um bem imaterial e, no que diz respeito à natureza jurídica dos bens imateriais, parece mais acertado o posicionamento da corrente doutrinária que afirma tratar-se de direito de propriedade sui generis, o que permite aplicar o instituto do direito de propriedade aos bens imateriais, observando apenas certas peculiaridades, em razão da especificidade da natureza do objeto.

Sobre a teoria do direito de propriedade sui generis, MAITÊ FABBRI MORO afirma:

\footnotetext{
"O direito de propriedade sui generis não nega o direito de propriedade, mas alerta para a especificidade do regime jurídico que deve ser empregado para os bens imateriais. É um regime particular adaptado aos bens incorpóreos, podendo, por isso, ser considerado o regime jurídico mais adequado para tutelá-los."11
}

O regime jurídico sui generis adapta-se às limitações impostas pelo legislador aos bens incorpóreos e supera as eventuais dificuldades que a aplicação do instituto do direito de propriedade clássico traria.

Em relação aos tipos de marca existentes, a classificação adotada atualmente considera as marcas de acordo com a sua origem, utilização ou apresentação visual.

Quanto à origem, as marcas podem ser classificadas como nacionais ou estrangeiras:

(I) Marca nacional é aquela regularmente depositada no Brasil, por pessoa domiciliada no País;

(II) Marca estrangeira é aquela regularmente depositada no Brasil por pessoa não domiciliada no país ou aquela que, depositada regularmente em país vinculado a acordo ou tratado do qual o Brasil seja partícipe, é também

\footnotetext{
${ }^{10}$ MORO, Maitê Cecília Fabbri. Direito de marcas: abordagem das marcas notórias na Lei $n^{\circ}$ 9.279/1996 e nos acordos internacionais. São Paulo: Revista dos Tribunais, 2003. p. 35. A autora traz interessante explanação acerca das funções secundárias da marca.

${ }^{11}$ MORO, Maitê Cecília Fabbri. Direito de marcas: abordagem das marcas notórias na Lei $n^{\circ}$ 9.279/1996 e nos acordos internacionais. São Paulo: Revista dos Tribunais, 2003. p. 52.
}

Revista Brasileira de Direito Internacional, Curitiba, v.4, n.4, jul./dez.2006 
depositada no território nacional no prazo estipulado no respectivo acordo ou tratado, com reivindicação de prioridade em relação à data do primeiro pedido.

No tocante à forma de utilização da marca, a legislação brasileira atual prevê três diferentes roupagens: marca de produto ou serviço, marca de certificação ou marca coletiva:

(I) Marca de produto ou serviço é aquela usada para distinguir produto ou serviço de outro idêntico, semelhante ou afim, de origem diversa. É o tipo de marca mais comumente encontrado no ambiente comercial. O titular do registro da marca de produto ou serviço detém o direito de usá-la com exclusividade, oponível a terceiros que pretendam se utilizar de sua reputação, ficando a seu critério a concessão de licenças de uso;

(II) Marca de certificação, por sua vez, é aquela usada para atestar a conformidade de um produto ou serviço com determinadas normas ou especificações técnicas, notadamente quanto à qualidade, natureza, material utilizado e metodologia empregada. As empresas cujos produtos ou serviços atendam a essas especificações estão automaticamente licenciadas a utilizar a marca. A entidade titular da marca deverá controlar e fiscalizar o uso da marca bem como aferir a adequação aos produtos ou serviços aos critérios previamente estabelecidos;

(III) Marca coletiva designa-se aquela usada para identificar produtos ou serviços provindos de membros de uma determinada entidade. Todos os membros filiados à entidade são automaticamente licenciados a usar a marca, ficando sujeitos a um regulamento que contém as condições e proibições de uso.

O antigo Código de Propriedade Industrial trazia classificação diversa quanto à utilização das marcas: tratava das marcas de indústria (utilizadas pelo industrial), marcas de comércio (utilizadas pelos comerciantes), marcas de serviço (utilizadas pelos prestadores de serviços) e marcas genéricas (empregadas para identificar uma gama de produtos, cada qual individualizado por uma marca específica).

Atualmente, deixou-se de diferenciar as marcas de indústria das marcas de comércio, passando a denominá-las conjuntamente como marcas 
de produto, assim como também não mais se utiliza da distinção entre marca genérica e marca específica.

Por fim, quanto à apresentação visual, as marcas podem ser nominativas, figurativas, mistas ou tridimensionais:

(I) Marca nominativa é constituída por uma denominação pura e simples, constituída por uma ou mais palavras no sentido amplo do alfabeto romano, compreendendo, também, os neologismos e as combinações de letras e/ou algarismos romanos e/ou arábicos;

(II) Marca figurativa constitui-se de uma imagem, uma figura, um emblema, uma letra ou algarismo isolado e grafado de maneira estilizada, ou um ideograma de línguas;

(III) Marca mista é constituída pela combinação de elementos nominativos e elementos figurativos ou de elementos nominativos com grafia estilizada;

(IV) Marca tridimensional é constituída por uma figura em três dimensões; normalmente a forma plástica (configuração física) de produto ou de embalagem, com capacidade distintiva em si mesma e dissociada de qualquer efeito técnico.

\section{REGISTRABILIDADE}

Cunho distintivo, novidade, veracidade e caráter lícito são os requisitos necessários para a obtenção de um registro marcário, segundo os ensinamentos de GAMA CERQUEIRA ${ }^{12}$.

O cunho distintivo apresenta-se sob dois aspectos: deve a marca ser característica em si mesma, possuir cunho próprio, e distinguir-se das outras marcas já empregadas.

A novidade da marca deve ser entendida de modo relativo, bastando para ser considerada nova que a marca não tenha sido usada para assinalar produtos ou serviços idênticos ou semelhantes; deve ser apreciada, portanto, em relação aos produtos ou serviços a que se aplica.

12 CERQUEIRA, João da Gama. Tratado da Propriedade Industrial. vol. I. Rio de janeiro: Revista Forense, 1956. p. 369-378.

Revista Brasileira de Direito Internacional, Curitiba, v.4, n.4, jul./dez.2006 
A veracidade, por sua vez, é exigida para que o titular não utilize a marca visando a enganar o público sobre a origem ou a qualidade do produto ou serviço que assinale.

Já o caráter lícito da marca se impõe para que o sinal adotado não seja escandaloso, contrário à moral, aos bons costumes ou à ordem pública ou, ainda, proibido por lei.

A Lei de Propriedade Industrial, após apresentar no art. 122 o que pode ser objeto de registro como marca de uma forma bastante ampla, abrangendo todos os sinais que sejam distintivos, visualmente perceptíveis e não proibidos, traz em seu art. 124 um rol bastante detalhado dos sinais que não são suscetíveis de registro. ${ }^{13}$ São, em geral, marcas ilícitas, sinais que podem

\begin{abstract}
${ }^{13}$ Art. 124. Não são registráveis como marca: I - brasão, armas, medalha, bandeira, emblema, distintivo e monumento oficiais, públicos, nacionais, estrangeiros ou internacionais, bem como a respectiva designação, figura ou imitação; II - letra, algarismo e data, isoladamente, salvo quando revestidos de suficiente forma distintiva; III - expressão, figura, desenho ou qualquer outro sinal contrário à moral e aos bons costumes ou que ofenda a honra ou imagem de pessoas ou atente contra liberdade de consciência, crença, culto religioso ou idéia e sentimento dignos de respeito e veneração; IV - designação ou sigla de entidade ou órgão público, quando não requerido o registro pela própria entidade ou órgão público; V - reprodução ou imitação de elemento característico ou diferenciador de título de estabelecimento ou nome de empresa de terceiros, suscetível de causar confusão ou associação com estes sinais distintivos; VI - sinal de caráter genérico, necessário, comum, vulgar ou simplesmente descritivo, quando tiver relação com o produto ou serviço a distinguir, ou aquele empregado comumente para designar uma característica do produto ou serviço, quanto à natureza, nacionalidade, peso, valor, qualidade e época de produção ou de prestação do serviço, salvo quando revestidos de suficiente forma distintiva; VII - sinal ou expressão empregada apenas como meio de propaganda; VIII - cores e suas denominações, salvo se dispostas ou combinadas de modo peculiar e distintivo; IX - indicação geográfica, sua imitação suscetível de causar confusão ou sinal que possa falsamente induzir indicação geográfica; $X$ - sinal que induza a falsa indicação quanto à origem, procedência, natureza, qualidade ou utilidade do produto ou serviço a que a marca se destina; XI - reprodução ou imitação de cunho oficial, regularmente adotada para garantia de padrão de qualquer gênero ou natureza; XII reprodução ou imitação de sinal que tenha sido registrado como marca coletiva ou de certificação por terceiro, observado o disposto no art. 154; XIII - nome, prêmio ou símbolo de evento esportivo, artístico, cultural, social, político, econômico ou técnico, oficial ou oficialmente reconhecido, bem como a imitação suscetível de criar confusão, salvo quando autorizados pela autoridade competente ou entidade promotora do evento; XIV - reprodução ou imitação de título, apólice, moeda e cédula da União, dos Estados, do Distrito Federal, dos Territórios, dos Municípios, ou de país; XV - nome civil ou sua assinatura, nome de família ou patronímico e imagem de terceiros, salvo com consentimento do titular, herdeiros ou sucessores; XVI pseudônimo ou apelido notoriamente conhecidos, nome artístico singular ou coletivo, salvo com consentimento do titular, herdeiros ou sucessores; XVII - obra literária, artística ou científica, assim como os títulos que estejam protegidos pelo direito autoral e sejam suscetíveis de causar confusão ou associação, salvo com consentimento do autor ou titular; XVIII - termo técnico usado na indústria, na ciência e na arte, que tenha relação com o produto ou serviço a distinguir; XIX - reprodução ou imitação, no todo ou em parte, ainda que com acréscimo, de marca alheia registrada, para distinguir ou certificar produto ou serviço idêntico, semelhante ou afim, suscetível de causar confusão ou associação com marca alheia; XX - dualidade de
\end{abstract}

Revista Brasileira de Direito Internacional, Curitiba, v.4, n.4, jul./dez.2006 
atentar contra a moral, os bons costumes ou a ordem pública (incisos I e III), sinais que podem induzir o consumidor em erro quanto à origem, natureza ou qualidade do produto ou serviço (incisos IV, V, VII, IX, X, XI, XII, XIII, XIV, XIX e XXIII), sinais desprovidos de capacidade distintiva (incisos II, VI, VIII, XVIII, XX e XXI) e sinais que violam direitos de personalidade ou direitos de propriedade intelectual (incisos XV, XVI, XVII, XXII e XXIII). ${ }^{14}$

Dentre os incisos do art. 124 da LPI, há alguns a serem comentados, em razão de sua recorrente aplicação na solução de conflitos marcários.

$O$ inciso $V$ estabelece que não é registrável como marca a reprodução ou a imitação de elemento característico ou diferenciador de título de estabelecimento ou nome de empresa de terceiros, suscetível de causar confusão ou associação com estes sinais distintivos. Esse dispositivo corrobora a proteção jurídica do nome empresarial assegurada pelo art. 5ㅇ, XXIX da Constituição Federal e pelo art. 8o da Convenção da União de Paris (CUP):

\footnotetext{
“CF, Art. 5, XXIX - a lei assegurará aos autores de inventos industriais privilégio temporário para sua utilização, bem como proteção às criações industriais, à propriedade das marcas, aos nomes de empresas e a outros signos distintivos, tendo em vista o interesse social e o desenvolvimento tecnológico e econômico do País."

"CUP, Art. $8^{\circ}$ - O nome comercial será protegido em todos os países da União sem obrigatoriedade de depósito ou registro, que faça ou não parte de uma marca de indústria ou de comércio."
}

Quem emprega marcas desse gênero revela, frequentemente, o intuito de se aproveitar da idoneidade ou do prestígio de outro empresário, mesmo que não seja dele concorrente. ${ }^{15}$

marcas de um só titular para o mesmo produto ou serviço, salvo quando, no caso de marcas de mesma natureza, se revestirem de suficiente forma distintiva; XXI - a forma necessária, comum ou vulgar do produto ou de acondicionamento, ou, ainda, aquela que não possa ser dissociada de efeito técnico; XXII - objeto que estiver protegido por registro de desenho industrial de terceiro; e XXIII - sinal que imite ou reproduza, no todo ou em parte, marca que o requerente evidentemente não poderia desconhecer em razão de sua atividade, cujo titular seja sediado ou domiciliado em território nacional ou em país com o qual o Brasil mantenha acordo ou que assegure reciprocidade de tratamento, se a marca se destinar a distinguir produto ou serviço idêntico, semelhante ou afim, suscetível de causar confusão ou associação com aquela marca alheia.

${ }^{14}$ LOUREIRO, Luiz Guilherme de A. V. A lei de propriedade industrial comentada. São Paulo: Lejus, 1999. p. 239.

${ }^{15}$ CERQUEIRA, João da Gama. Tratado da propriedade industrial. vol. II. Rio de Janeiro: Forense, 1956. p. 32.

Revista Brasileira de Direito Internacional, Curitiba, v.4, n.4, jul./dez.2006 
$\mathrm{O}$ inciso $\mathrm{VI}$ do referido art. 124 afirma a essencialidade da função distintiva da marca ao dispor que não são objeto de registro, sinais de caráter genérico, necessário, comum, vulgar ou simplesmente descritivos, quando apresentarem relação com o produto ou serviço a distinguir, ou aqueles sinais empregados comumente para designar uma característica do produto ou serviço, quanto à natureza, nacionalidade, peso, valor, qualidade e época de produção ou de prestação do serviço, salvo quando revestidos de suficiente forma distintiva.

Para fins da aplicação do inciso VI, a Resolução n 51 de 1997 do INPI, que estabelece diretrizes provisórias para análise de marcas, considera:

\begin{abstract}
“a) Sinal de caráter genérico - o termo ou expressão nominativa ou a sua representação gráfica que, sem ser de caráter necessário em relação ao produto ou serviço, ou indicativo de natureza, nacionalidade, peso, valor, qualidade e época de produção ou de prestação de serviço, não pode individualizá-lo, sob pena de atentar contra o direito dos concorrentes.

b) Sinal de caráter necessário - o termo ou expressão nominativa ou o elemento figurativo indispensável para designar ou representa o produto, a mercadoria ou o serviço, ou, ainda, seus insumos. Exemplo: TOMATE - para tomates; AGUARDENTE - para aguardente de cana-de-açúcar.

c) Sinal de caráter comum ou vulgar - o termo ou expressão nominativa ou o elemento figurativo que, embora não corresponda ao nome ou à representação pelo qual o produto, a mercadoria ou o serviço foram originariamente identificados, tenha sido consagrado, pelo uso corrente, para essa finalidade, integrando, assim, a linguagem comercial. Exemplo: CACHAÇA - para aguardente de cana-de-açúcar; PINGA - aguardente de cana-de-açúcar.

d) Sinal simplesmente descritivo - o termo ou expressão nominativa que não se preste a distinguir produto ou serviço, mas que vise a indicar seu destino, sua aplicação, ou a descrevê-lo em sua própria constituição. Exemplo: MARCATEMPO - para cronômetros.

e) que tenha relação com o produto, mercadoria ou serviço - aquele que guarde vínculo direto ou imediato com o que visa assinalar. Exemplo: PISANTE - para sapatos; TOMATO - para molhos.

f) Sinal empregado comumente para designar - aquele cujo uso reiterado resultou em sua consagração na linguagem comercial corrente para denominar uma característica do produto ou serviço; f.1) natureza: IN NATURA; f.2) nacionalidade: BRASILEIRO; f.3) peso: QUILO - para cereais; f.4) valor: CINCO ESTRELAS - para serviços de hotelaria; f.5) qualidade: SABOROSO - para pães; f.6) época de produção ou de prestação de serviço: SAFRA 1942 - para bebidas." 16
\end{abstract}

O sinal cujo uso seja indispensável para identificação de todos os produtos ou serviços de uma mesma natureza não é considerado distintivo e,

${ }^{16}$ BRASIL. INPI. Resolução $n^{\circ} 51$ de 1997. Diretrizes Provisórias de Análise de Marcas.p. 3033.

Revista Brasileira de Direito Internacional, Curitiba, v.4, n.4, jul./dez.2006 
portanto, não pode ser registrado como marca. Nas palavras de LUIZ GUILHERME LOUREIRO, "o monopólio do nome ou sinal genérico em benefício de um comerciante poderia gerar uma exclusividade inadmissível e injusta, além de prejudicial aos concorrentes, que não teriam como apresentar seus produtos". ${ }^{17}$

No entanto, cabe frisar que termos inicialmente considerados genéricos, conjuntamente, podem dar origem a uma marca complexa registrável, se revestida de originalidade.

O inciso VII, por sua vez, traz a proibição de registrabilidade de marca que constitua um sinal ou expressão empregada apenas como meio de propaganda. Essa previsão constitui uma novidade em relação à lei anterior, que permitia o registro de expressões de propaganda, ou slogans. Por conseguinte, após a entrada em vigor da Lei o 9.279/96, as empresas precisaram buscar na legislação de direitos autorais e concorrência desleal a proteção para os seus slogans, não mais podendo contar com a proteção marcária.

O inciso XV prevê a não registrabilidade de nome civil ou assinatura, nome de família ou patronímico e imagem de terceiros, salvo com o consentimento do titular, herdeiros ou sucessores. Nesse mesmo sentido, o inciso XVI estabelece proibição ao registro de pseudônimos ou apelidos notoriamente conhecidos e nomes artísticos como marca.

Não raro, na prática mercantil, ocorre a reprodução ou a imitação, por parte de alguns empresários, de marcas alheias. Com o intuito de evitar condutas dessa natureza, o inciso XIX confere proteção aos titulares de marcas e aos consumidores, assegurando que não serão concedidos registros para reproduções ou imitações de marcas que visem distinguir ou certificar produto ou serviço idêntico, semelhante ou afim, suscetível de causar confusão ou associação com marca registrada de outrem.

A aplicação desta norma, segundo JOSÉ ANTÔNIO FARIA CORREA, independe de prova do reconhecimento da marca violada em nosso país, uma vez que trata de hipótese de fraude, pura e simples, e não da proteção de

${ }^{17}$ LOUREIRO, Luiz Guilherme de A. V. A lei de propriedade industrial comentada. São Paulo: Lejus, 1999. p. 243.

Revista Brasileira de Direito Internacional, Curitiba, v.4, n.4, jul./dez.2006 
marcas notoriamente conhecidas. É o que sustenta em seu artigo publicado na Revista da Associação Brasileira de Propriedade Industrial (ABPI) nำ 17, jul/ago 1995, ao interpretar o ainda Projeto de Lei no 115/93, posteriormente Lei no 9.279/96:

\begin{abstract}
“Assim como a proteção às marcas notoriamente conhecidas não depende de comprovação do intuito do requerente, a proteção geral contra a fraude não pressupõe o caráter notório do sinal. O que se pesquisa, aqui, é o conteúdo subjetivo do ato ilícito, que contamina o uso que se possa fazer da marca alheia."18
\end{abstract}

Para que fique caracterizada a proibição legal ao registro, há necessidade da ocorrência de três fatores, quais sejam: (I) que ocorra reprodução ou imitação de marca previamente registrada; (II) que exista identidade ou afinidade entre os setores de atividade e, consequentemente, dos produtos ou serviços em conflito; e (III) que haja possibilidade de erro ou confusão pelos consumidores em virtude dos outros dois fatores. ${ }^{19}$

O Superior Tribunal de Justiça proferiu decisão, ainda na vigência do Código da Propriedade Industrial, cujo artigo 65 '17' corresponde ao atual art. 124, inc. XIX, da Lei no 9.279/96, que determina a coexistência pacífica de duas marcas semelhantes desde que não impliquem erro, dúvida ou confusão:

\footnotetext{
"Possível é a coexistência de duas marcas no universo mercantil, mesmo que a mais recente contenha reprodução parcial da mais antiga e que ambas se destinem à utilização em um mesmo ramo de atividade (...), se inexistente a possibilidade de erro, dúvida ou confusão a que alude o art. 65 , n. 17, da Lei 5.772/71.,"20
}

Pode-se, portanto, inferir que, na avaliação de eventual conflito marcário, importa menos saber se as marcas são iguais, semelhantes ou se estão inseridas na mesma classe, e mais se são passíveis de induzir o consumidor em erro ou confusão quando da escolha e aquisição do bem almejado ou contratação do serviço prestado. No entendimento jurisprudencial

\footnotetext{
${ }^{18}$ CORREA, José Antônio Faria. Revista da ABPI no 17, jul/ago 1995.

${ }^{19}$ PAES, Paulo Roberto Tavares. Propriedade Industrial: Lei $n^{\circ}$ 9.279, de 14.05.1996. Rio de Janeiro: Forense, 2000. p. 119.

${ }^{20}$ Superior Tribunal de Justiça, REsp 37646/RJ, Rel. Min. Sálvio de Figueiredo Teixeira, DJ de 13/06/1994.
}

Revista Brasileira de Direito Internacional, Curitiba, v.4, n.4, jul./dez.2006 
apresentado, não havendo suscetibilidade de erro do consumidor, inexistem motivos para que o pedido de registro seja indeferido.

Ainda como forma de evitar a imitação e a reprodução de marcas, 0 inciso XXIII do art. 124 da LPI prevê a não registrabilidade de sinal que faça alusão à marca de terceiro sediado ou domiciliado em território nacional ou em país com o qual o Brasil mantenha acordo ou que assegure reciprocidade de tratamento, que o requerente evidentemente não poderia desconhecer em razão de sua atividade, se a marca se destinar a distinguir produto ou serviço idêntico, semelhante ou afim, suscetível de causar confusão ou associação com aquela marca alheia.

A apreciação das imitações ou reproduções constitui questão de fato a ser decidida pelo juiz ou pela autoridade administrativa, conforme o caso. No entanto, essa apreciação não pode se deixar de observar determinados princípios.

O tratadista JOÃO DA GAMA CERQUEIRA ${ }^{21}$ estabelece três princípios a serem seguidos pelo examinador:

" $1^{\circ}$, as marcas não devem ser confrontadas e comparadas, mas apreciadas
sucessivamente, a fim de se verificar se a impressão causada por uma recorda
a impressão deixada pela outra; $2^{\circ}$, as marcas devem ser apreciadas, tendo-se
em vista não as suas diferenças, mas as suas semelhanças; $3^{\circ}$, finalmente,
deve-se decidir pela impressão de conjunto das marcas e não pelos seus
detalhes."

A imitação das marcas, segundo esse autor, é fenômeno de difícil percepção à primeira vista e, como tal, capaz de criar confusão com a marca legítima:

\footnotetext{
“A imitação pode assumir as mais variadas formas, sendo tarefa impossível indicá-las todas. Tanto nos casos propriamente de contrafação, isto é, nos casos de delito, como naqueles em que se procura registrar marca semelhante à outra já registrada, o contrafator recorre a toda sorte de artifícios para alcançar os fins visados e, ao mesmo tempo, embaraçar a ação do prejudicado. Procura dar a nova marca aspecto semelhante, capaz de criar confusão com a marca legítima, mas precavidamente introduz elementos novos diferentes, às vezes bastantes sensíveis, os quais, sem prejudicar a
}

${ }^{21}$ CERQUEIRA, João da Gama. Tratado da Propriedade Industrial. vol. II. Rio de janeiro: Revista Forense, 1956, p. 68-69.

Revista Brasileira de Direito Internacional, Curitiba, v.4, n.4, jul./dez.2006 
impressão de conjunto da marca, possam servir para a sua defesa, no caso de processo ou impugnação.

O contrafator não visa apenas a iludir o consumidor, mas também a justiça ou a repartição incumbida do registro. Por isso, tanto mais hábil é a imitação, tanto mais perigosa se torna. Para desmascará-la há de se possuir alguma argúcia, uma sensibilidade especial, uma intuição capaz de descobrir o que se acha oculto através daquilo que propositadamente se ostenta.

As marcas imitadas, pode-se dizer, distinguem-se das legítimas pelo que mostram e com elas se assemelham pelo que escondem."22

A reprodução das marcas, por sua vez, é fenômeno que não oferece grandes dificuldades quanto a sua percepção, dada a simplicidade de seu conceito. Nesse sentido, afirma:

\begin{abstract}
"A reprodução da marca é a cópia servil, idêntica, sem disfarces. Reproduzir é copiar. Se a marca levada a registro é igual a outra anteriormente registrada e em vigor, o registro não poderá ser concedido. [V]erifica-se a hipótese quando a denominação é reproduzida, ainda que em caracteres diferentes ou que a ela se acrescentem outros elementos.

Tratando-se da parte essencial ou característica da marca, isto é suficiente para impedir o registro, pois a lei proíbe expressamente tanto a reprodução integral como a reprodução parcial. Não importa que à parte característica reproduzida se acrescentem outros elementos, que tornem a marca diferente da anterior; prevalece a reprodução parcial como impedimento do registro, não se devendo cogitar da semelhança do conjunto.,23
\end{abstract}

\title{
5 PROCESSO ADMINISTRATIVO DE REGISTRO DE MARCA
}

O direito industrial brasileiro adota o sistema de tramitação de pedidos de marca conhecido como sistema de exame prévio, pelo qual o órgão responsável examina as condições de registrabilidade da marca antes de decidir pela concessão do registro. ${ }^{24}$

No Brasil, o órgão que desempenha essa função é o Instituto Nacional de Propriedade Industrial (INPI), autarquia federal ligada ao Ministério do Desenvolvimento, Indústria e Comércio Exterior, criada pela Lei № 5.648 de 1970 e regulada pelo Decreto ํo 68.104 de 1971 .

\footnotetext{
${ }^{22}$ CERQUEIRA, João da Gama. Tratado da Propriedade Industrial, $2^{a}$ edição, vol. II, São Paulo: Revista dos Tribunais, 1982. p. 915-916.

${ }^{23}$ CERQUEIRA, João da Gama. Tratado da Propriedade Industrial. vol. II. Rio de janeiro: Revista Forense, 1956, p. 57-60.

${ }^{24}$ COELHO, Fábio Ulhoa. Curso de direito comercial, vol. 1. São Paulo: Saraiva, 2004. p. 162. Explica os demais sistemas de tramitação encontrados mundialmente para registro de propriedade industrial.
} 
$O$ ato administrativo de registro praticado pelo INPI é constitutivo do direito industrial de exclusividade de exploração econômica do bem. A decisão administrativa do INPI não impede que os interessados, em se sentindo lesados, possam discutir judicialmente acerca do atendimento dos requisitos legais de registrabilidade.

Antes de se lançar ao depósito de marca, é aconselhável que se realize uma busca prévia de anterioridades junto ao banco de dados do INPI, com relação à atividade que o signo visa assinalar, a fim de se verificar se já existem marcas colidentes anteriormente depositadas por outro titular.

Para obter o registro de uma marca no Brasil, é necessário que se apresente um pedido ao INPI, que o examinará com base nas normas legais estabelecidas pela Lei de Propriedade Industrial.

Podem requerer registro de marca as pessoas físicas ou jurídicas de direito público ou de direito privado, sendo que, para as pessoas de direito privado, existe uma restrição: somente podem requerer registro de marca relativo à atividade que exerçam efetiva e licitamente, de modo direto ou por meio de empresas que controlem direta ou indiretamente, devendo declarar, no próprio requerimento, esta condição.

Em se tratando de uma marca coletiva, o seu registro apenas poderá ser requerido pela pessoa jurídica representativa da coletividade. E, no caso de marca de certificação, o registro somente poderá ser requerido por pessoa sem interesse comercial ou industrial direto no produto ou serviço atestado.

$\mathrm{O}$ art. 155 da Lei de Propriedade Industrial estabelece os documentos necessários para instrução do pedido de marca, quais sejam: o requerimento; as etiquetas, quando se tratar de marca figurativa, mista ou tridimensional; e o comprovante do pagamento da retribuição relativa ao depósito.

O pedido deve se referir a um único sinal distintivo e os documentos que o instruem devem ser apresentados em língua portuguesa. Se algum dos documentos exigidos estiver em língua estrangeira, sua tradução simples deverá ser apresentada no ato do depósito ou dentro dos sessenta dias subseqüentes, sob pena do INPI não o considerar.

Revista Brasileira de Direito Internacional, Curitiba, v.4, n.4, jul./dez.2006 
Após ser apresentado o pedido de registro de marca, o INPI realizará o exame formal preliminar, em relação às condições de instrução do pedido. Se estiver convenientemente instruído, o pedido é protocolado, considerando-se a data de depósito como a de sua apresentação (art. 156, LPI). No entanto, se a instrução não estiver completa, serão fixadas exigências, que deverão ser atendidas pelo requerente da marca no prazo de cinco dias, sob pena do pedido ser considerado inexistente (art. 157, LPI).

Depois de realizado o depósito, segue-se a publicação do pedido de marca, abrindo-se um prazo de sessenta dias para que qualquer interessado apresente sua oposição (art. 158, LPI). É, portanto, deveras importante que os titulares de direitos marcários acompanhem as publicações semanais do INPI, na Revista de Propriedade Industrial (RPI), a fim de prevenir que novos pedidos de marca de terceiros violem seus interesses.

Findo o prazo para apresentação de oposições, o depositante será intimado acerca das eventuais oposições que foram ofertadas contra o seu pedido de marca, para, em um prazo de sessenta dias, defender a sua pretensão ao registro, por meio de manifestação à oposição.

A partir daí, o INPI realizará a análise das condições de registrabilidade (cunho distintivo, novidade, veracidade e caráter lícito) e poderá impor exigências ao requerente da marca, visando à adequação do pedido para o deferimento do registro (art. 159, LPI). Após concluir seu exame, preferirá a decisão do pedido, deferindo ou não o registro da marca.

Se indeferido o pedido de marca, caberá a interposição de recurso por seu titular, no prazo de sessenta dias contados da publicação do indeferimento. O recurso será decidido pelo Presidente do INPI e, em havendo a manutenção do indeferimento, encerrar-se-á a instância administrativa, sendo o pedido arquivado.

Por outro lado, se deferido o pedido de marca, seu titular terá um prazo de sessenta dias, contados da publicação do deferimento, para comprovar junto ao INPI o pagamento das taxas finais relativas à expedição do certificado de registro e ao primeiro decênio de sua vigência (art. 162, LPI). Somente então será concedido o registro e expedido o certificado de registro da marca, 
no qual constarão o tipo de marca, o número e a data do registro, o nome, a nacionalidade e o domicílio de seu titular, os produtos ou serviços, as características do registro e a existência ou não de prioridade estrangeira (art. 164, LPI).

Por fim, cumpre frisar que todos os prazos previstos são contados a partir da data de publicação dos despachos do INPI na Revista da Propriedade Industrial (RPI), a qual possui periodicidade semanal.

Como forma de elucidar os trâmites do processo administrativo de registro de marcas que ocorre no Instituto Nacional de Propriedade Industrial, exponha-se o seguinte esquema:

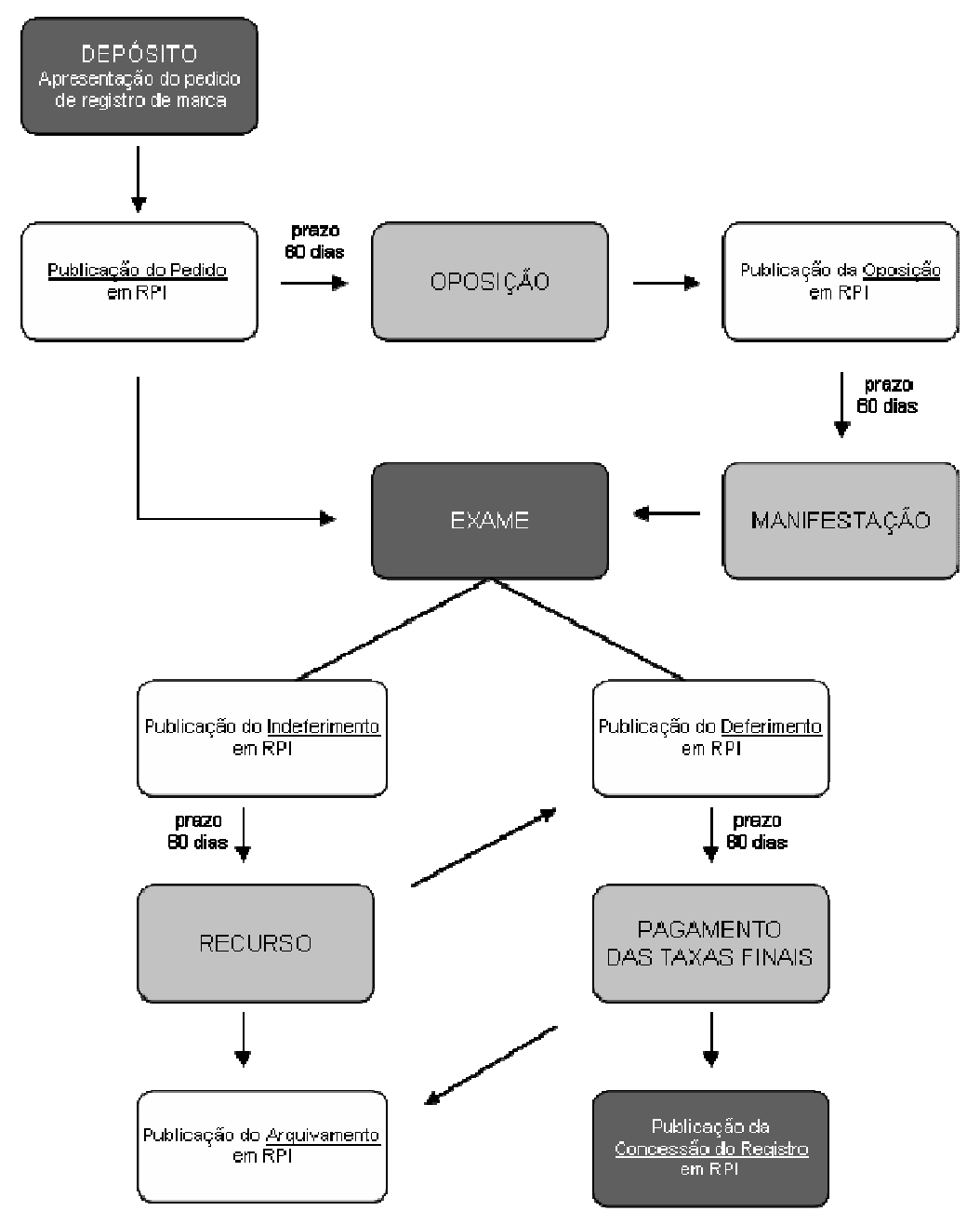

Caso seja de interesse do titular do pedido ou registro de marca perante o INPI depositá-la em outro país com o qual o Brasil mantenha acordo internacional, terá o direito de prioridade assegurado, por meio do qual o novo 
depósito alienígena não será invalidado nem prejudicado por fatos ocorridos durante o prazo de prioridade previsto no acordo.

Exemplifique-se: ao realizar depósito de marca em país signatário da Convenção da União de Paris (CUP), o titular de pedido ou registro de marca no Brasil terá direito de prioridade em relação a eventuais marcas semelhantes depositadas naquele país após a data do depósito da marca no Brasil. Daí a importância da data do depósito do pedido, pois serve como marco inicial, a partir do qual o titular tem direito de prioridade nos demais países signatários da convenção.

\section{DA VIGÊNCIA DO REGISTRO DE MARCA, DA CESSÃo E DA LICENÇA DE USO DE MARCA}

O registro de marca vigorará pelo prazo de dez anos, contados da data da concessão do registro, prorrogáveis por períodos iguais e sucessivos.

Em havendo interesse do titular em continuar utilizando a marca com exclusividade, deverá formular um pedido de prorrogação durante o último ano de vigência do registro e pagar a retribuição referente à proteção de mais um decênio (art. 133, §1ํ, LPI). Ou ainda, poderá o titular solicitar a prorrogação do registro após o término da vigência, dentro de seis meses, mas será necessário o pagamento de retribuição adicional (art. 133, §2º, LPI).

Com relação à cessão de direitos marcários, tanto o pedido de registro como o registro de marca podem ser cedidos, desde que o cessionário atenda aos requisitos legais do art. 128 da LPI para requerer tal registro.

A cessão deverá compreender todos os registros ou pedidos de titularidade do cedente, de marcas iguais ou semelhantes, relativas a produtos ou serviços idênticos, semelhantes ou afins, sob pena dos pedidos não cedidos serem arquivados e os registros, cancelados (art. 135, LPI).

A Lei 9.279/96 manteve assim o princípio da universalidade da cessão, previsto no art. 89 do antigo Código de Propriedade Industrial, segundo o qual, no caso de transferência, todos os registros e pedidos de marcas iguais ou semelhantes, referentes à mesma atividade, devem ser repassadas em bloco. 
DENIS BARBOSA explica: "O motivo é a impossibilidade de conviver modalidades da mesma marca, concedidas apenas em atenção à unicidade do titular, em condições que se presumem concorrenciais" ${ }^{25}$.

Quando da concepção da faculdade de cessão de marcas em nosso ordenamento jurídico, havia a vedação da transferência da marca sem o estabelecimento a que estivesse vinculada. Atualmente, há liberdade de cessão de marca independentemente do estabelecimento, assim estabelecida pelo TRIPS:

\footnotetext{
“(TRIPs) Art. 21 - Os Membros poderão determinar as condições para a concessão de licenças de uso e cessão de marcas, no entendimento de que não serão permitidas licenças compulsórias e que o titular de uma marca registrada terá o direito de ceder a marca, com ou sem a transferência do negócio ao qual a marca pertença."
}

Diferentemente do mecanismo de cessão, em que há a transferência total e definitiva dos direitos sobre determinada marca, o titular do registro ou do pedido de registro pode celebrar contrato de licença de uso da marca, sem prejuízo de seu direito de exercer o controle efetivo sobre as especificações, natureza e qualidade dos respectivos produtos ou serviços. Inclusive, poderá investir o licenciado de todos os poderes para agir em defesa da marca, sem prejuízo dos seus próprios direitos.

Quanto à eficácia, o contrato de licença de uso de marca gera efeitos entre as partes desde o momento de sua assinatura, mas, para que produza efeitos em relação a terceiros, o contrato de licença deverá ser averbado no INPI.

Uma novidade em relação ao Código de Propriedade Industrial anterior é que a hipótese de o licenciante controlar a qualidade dos produtos e serviços do licenciado apresenta-se agora como um direito e não mais como um dever. ${ }^{26}$

\footnotetext{
${ }^{25}$ BARBOSA, Denis Borges. Licenças e Cessões na Propriedade Industrial. p. 11. In: $<$ denisbarbosa.addr.com>, acesso em 03/01/2007.

26 BARBOSA, Denis Borges. Licenças e Cessões na Propriedade Industrial. p. 12. In: $<$ denisbarbosa.addr.com>, acesso em 03/01/2007.
}

Revista Brasileira de Direito Internacional, Curitiba, v.4, n.4, jul./dez.2006 


\section{NULIDADE DO REGISTRO}

Após a publicação da concessão do registro da marca, terceiros interessados, por acreditarem ter sido concedido o registro com infringência ao disposto na LPI, poderão requerer a instauração de processo administrativo de nulidade, a fim de que a decisão do INPI seja revista administrativamente.

O processo de nulidade poderá ser instaurado de ofício ou mediante requerimento de qualquer pessoa com legítimo interesse, no prazo de 180 dias contados da data da expedição do certificado de registro.

Como meio de anular o registro concedido pelo INPI, a Lei de Propriedade Industrial prevê também a ação de nulidade, que poderá ser proposta no prazo de até cinco anos da data de concessão do registro de marca e será apreciada pelo Poder Judiciário.

A ação de nulidade poderá ser proposta pelo INPI ou por qualquer pessoa com legítimo interesse, devendo ser ajuizada no foro da justiça federal. Atendidos os requisitos processuais, o juiz poderá determinar liminarmente a suspensão dos efeitos do registro e do uso da marca. Quando o INPI não for autor, deverá intervir no feito.

A nulidade do registro poderá ser total ou parcial, sendo condição para a nulidade parcial o fato de a parte subsistente poder ser considerada registrável. Eventual declaração de nulidade produzirá efeito a partir da data do depósito do pedido.

\section{DOS DIREITOS SOBRE A MARCA}

Os titulares de marcas têm seus direitos assegurados, em primeiro lugar, face à garantia constitucional conferida à propriedade industrial pelo art. 5o, inc. XXIX, da Constituição Federal de 1988:

\footnotetext{
"XXIX - a lei assegurará aos autores de inventos industriais privilégio temporário para sua utilização, bem como proteção às criações industriais, à propriedade das marcas, aos nomes de empresas e a outros signos distintivos, tendo em vista o interesse social e o desenvolvimento tecnológico e econômico do País."
}

Revista Brasileira de Direito Internacional, Curitiba, v.4, n.4, jul./dez.2006 
A propriedade da marca adquire-se pelo registro validamente concedido pelo INPI, conforme as disposições da Lei de Propriedade Industrial, sendo assegurado ao seu titular o uso exclusivo em todo o território nacional. A necessidade da formalidade do registro confirma o sistema atributivo como modo de concessão de exclusividade de uso ao titular de marca.

$\mathrm{O}$ art. 129 da LPI, em seu $\S 1^{\circ}$, traz uma inovação em relação à lei anterior. Institui o chamado direito de precedência, segundo o qual a pessoa de boa fé que utiliza no país marca idêntica ou semelhante, para distinguir ou certificar produto ou serviço idêntico, semelhante ou afim, há pelo menos seis meses na data da prioridade ou depósito da marca de terceiro, terá direito de precedência ao registro.

Além de garantir os direitos do titular do registro de marca (art.129, LPI), a lei também assegura direitos ao depositante que ainda não teve o seu registro concedido. $O$ art. 130 prevê que, ao titular da marca ou ao depositante é assegurado o direito de ceder seu registro ou pedido de registro, de licenciar seu uso e de zelar pela sua integridade material ou reputação. Nesse sentido, o pedido de registro de um titular garante-lhe a prioridade sobre eventuais marcas posteriores que venham a utilizar configurações semelhantes.

Conforme nos esclarecem DI BLASI et al::

\footnotetext{
"[A] finalidade básica do depósito é conceder ao pedido uma anterioridade, ou seja, a data a partir da qual não podem ser outorgados registros para marcas, dotadas de características similares, cujos pedidos de registro tenham sido requeridos posteriormente" ${ }^{27}$.
}

O direito de propriedade marcária não é absoluto, havendo algumas limitações que Ihe são legalmente impostas (art.132, LPI). Exemplifique-se: em que pese possuir direitos de exclusividade, o titular da marca de produto não poderá impedir que comerciantes ou distribuidores utilizem-na na promoção e comercialização do produto juntamente com seus sinais distintivos próprios.

Também não poderá o titular da marca impedir que fabricantes de acessórios utilizem-ma para indicar a destinação do produto, bem como não caberá impedir a livre circulação de produto colocado no mercado interno, por

${ }^{27}$ DI BLASI, Gabriel et al. A propriedade industrial. Rio de Janeiro: Forense, 2000, p. 178.

Revista Brasileira de Direito Internacional, Curitiba, v.4, n.4, jul./dez.2006 
si ou por outrem com seu consentimento. Ademais, não lhe é lícito impedir a citação da marca em discurso, obra científica ou literária ou qualquer outra publicação, desde que sem conotação comercial e sem prejuízo para seu caráter distintivo.

A proteção conferida às marcas é limitada basicamente por dois princípios: o princípio da territorialidade e o princípio da especialidade.

Pelo princípio da territorialidade tem-se que a propriedade de uma marca, conferida por seu registro em um determinado país, somente produz efeitos em seu território. Dessa forma, os direitos do titular da marca registrada no Brasil somente poderão ser exercidos no território nacional.

Ademais, independente da marca ser explorada em apenas algumas regiões do país, uma vez registrada a mesma estará protegida contra uso de terceiro, para produtos iguais ou semelhantes, em todo o território brasileiro.

Sobre o princípio da territorialidade, JOSÉ ROBERTO GUSMÃO explica:

“[O] princípio da territorialidade inerente ao direito de propriedade industrial, em geral, deriva do princípio maior da territorialidade das leis, segundo o qual as leis de determinado Estado são aplicáveis única e exclusivamente no território daquele Estado". 28

Há uma exceção a esse princípio. É o caso da marca notoriamente conhecida, que, mesmo não estando previamente depositada ou registrada no território brasileiro, goza de proteção especial no ramo de atividade de seu titular, em virtude de sua notoriedade internacional.

O segundo princípio basilar do direito das marcas é o princípio da especialidade, pelo qual a proteção do sinal distintivo vincula-se diretamente ao produto ou serviço assinalado pelo titular.

Ao depositar uma marca, faz-se necessário que o depositante especifique o tipo de produto ou serviço que ela se destinará a identificar. Essa especificação faz com que, após concedido o registro da marca, não se

${ }^{28}$ GUSMÃO, José Roberto. Marcas de alto renome, marcas notoriamente conhecidas e usurpação de signos distintivos. Seminário Nacional da Propriedade Intelectual: a nova Lei de Propriedade Industrial no contexto internacional. Anais, 1996. Apud MORO, Maitê Cecília Fabbri. Direito de marcas: abordagem das marcas notórias na Lei 9.279/1996 e nos acordos internacionais. São Paulo: Revista dos Tribunais, 2003. p. 64.

Revista Brasileira de Direito Internacional, Curitiba, v.4, n.4, jul./dez.2006 
possam aceitar registros de marcas iguais ou semelhantes para o mesmo tipo de produto ou serviço.

Sobre o princípio da especialidade, DENIS BARBOSA afirma que "a exclusividade de um signo se esgota nas fronteiras do gênero de atividades que ele designa" ${ }^{\prime 2}$. O que se realmente pretende é evitar a possibilidade de confusão por parte dos consumidores.

O consumidor não é técnico em propriedade industrial, conseqüentemente, é por meio da marca que o mesmo se guia para adquirir seus produtos. Portanto, os produtos ou serviços identificados por uma marca não devem levar os consumidores a adquiri-los imaginando ter associação com a marca de outro titular.

Para facilitar o registro de marcas e a busca de anterioridades, os produtos e serviços das mais diversas áreas de atuação foram divididos em classes, as quais exercem um papel meramente administrativo para o INPI.

Até 03 de janeiro de 2000, o Brasil adotava uma classificação nacional de produtos e serviços instituída pelo Ato Normativo $n^{\circ} 51$ de 1981. A partir de então, o INPI passou a adotar a $7^{a}$ edição da Classificação Internacional de Produtos e Serviços, proposta no Acordo de Nice. Em 2002, passou-se à $8^{\text {a }}$ edição e, em 2007, à 9a edição desta classificação, que contém 45 classes, sendo 34 referentes a produtos e 11 referentes a serviços.

GAMA CERQUEIRA afirma que o princípio da especialidade não é absoluto, por tratar sempre de questões de fato, sendo que as circunstâncias precisam ser consideradas ao se decidir sobre a novidade e possibilidade de confusão das marcas. ${ }^{30}$

Assim como o princípio da territorialidade, o princípio da especialidade comporta exceções. Uma das exceções desse princípio é a marca de alto renome, uma vez que ela possui proteção em todas as classes produtos e serviços, não se restringindo ao ramo de atuação de seu titular.

\footnotetext{
${ }^{29}$ BARBOSA, Denis Borges. Uma introdução à propriedade intelectual, vol. I. Rio de Janeiro: Lúmen Júris, 1997. p. 217.

${ }^{30}$ CERQUEIRA, João da Gama. Tratado de propriedade industrial. vol. I. Rio de janeiro: Forense, 1956. p. 371.
}

Revista Brasileira de Direito Internacional, Curitiba, v.4, n.4, jul./dez.2006 
No tocante à extinção dos direitos conferidos ao titulares de marca, o art. 142 da LPI estabelece quatro causas pelas quais o registro pode ser extinto: (I) expiração do prazo de vigência de registro sem que haja pedido de prorrogação; (II) renúncia do titular; (III) caducidade; e (IV) se o titular for residente no exterior e não manter procurador devidamente qualificado domiciliado no país.

Especificamente quanto à caducidade, o art. 143 da LPI determina que caducará o registro, a requerimento de qualquer pessoa com legítimo interesse se, decorridos cinco anos de sua concessão e o uso da marca não tiver sido iniciado no Brasil, bem como se o uso da marca tiver sido interrompido por mais de cinco anos consecutivos ou se a marca tiver sido usada com modificação que implique alteração de seu caráter distintivo original.

No entanto, cumpre ressaltar que não ocorrerá caducidade se o titular justificar o desuso da marca por razões legítimas, como por exemplo, o desuso por determinação judicial ou problemas alfandegários.

\section{PROTEÇÃO ESPECIAL: MARCA NOTORIAMENTE CONHECIDA E MARCA DE ALTO RENOME}

A Lei de Propriedade Industrial traz em seu bojo a previsão de proteção especial às chamadas marcas notoriamente conhecidas e marcas de alto renome.

Em relação às primeiras, o art. 126 dispõe que a marca que for notoriamente conhecida em seu ramo de atividade, goza de proteção especial naquele segmento de mercado, independente de estar registrado no INPI. Por conseguinte, quem tentar se apropriar de marca notoriamente conhecida, que evidentemente não Ihe pertença, terá seu pedido de marca indeferido pelo INPI, mesmo que não exista registro anterior daquela marca no Brasil. Tal dispositivo está em consonância com o estabelecido pelo art. 6ํㅡ, bis (I), da Convenção da União de Paris para Proteção da Propriedade Industrial:

\footnotetext{
“Art. $6^{\circ}$ bis (I) Os países da União comprometem-se a recusar ou invalidar o registro, quer administrativamente, se a lei do país o permitir, quer a pedido
}

Revista Brasileira de Direito Internacional, Curitiba, v.4, n.4, jul./dez.2006 
do interessado e a proibir o uso de marca de fábrica ou de comércio que constitua reprodução, imitação ou tradução, suscetíveis de estabelecer confusão, de uma marca que a autoridade competente do país do registro ou do uso considere que nele é notoriamente conhecida como sendo já marca de uma pessoa amparada pela presente Convenção, e utilizada para produtos idênticos ou similares. O mesmo sucederá quando a parte essencial da marca notoriamente conhecida ou imitação suscetível de estabelecer confusão com esta."

As segundas, por sua vez, as chamadas marcas de alto renome, são dotadas de proteção especial em todas as classes de produtos e serviços, ou seja, em todos os ramos de atividade e não apenas naquele de atuação de seu titular (art. 125, LPI).

Trata-se de uma exceção ao princípio da especialidade, pois sua proteção vai além dos produtos ou serviços especificados no pedido de registro da marca.

As marcas de alto renome eram tratadas pelo antigo Código de Propriedade Industrial sob o nomem juris de "marca notória", o que até hoje gera muita confusão com a denominação "marca notoriamente conhecida" supramencionada.

O art. 67 daquele diploma legal instituía a necessidade de um requerimento de registro especial ao INPI para que a marca tivesse um tratamento de "marca notória", sendo bastante criticado por consagrar uma situação de privilégio permanente, quando não necessariamente a notoriedade do sinal distintivo persistia até o final do prazo de validade do registro.

A LPI trouxe nova denominação para as "marcas notórias", chamandoas de marcas de alto renome, bem como instituiu um novo tratamento à matéria. Conferiu proteção especial às marcas de alto renome quando do surgimento de controvérsia com outro sinal marcário, apenas depois de restar comprovado o fenômeno do alto reconhecimento pelo público em geral naquele determinado momento.

$\mathrm{O}$ art. $2^{\circ}$ da Resolução $\mathrm{n}^{\circ} 121$ de 2005, do Instituto Nacional de Propriedade Industrial, apresenta a seguinte definição para marca de alto renome:

Revista Brasileira de Direito Internacional, Curitiba, v.4, n.4, jul./dez.2006 


\begin{abstract}
"Considera-se de alto renome a marca que goza de uma autoridade incontestável, de um conhecimento e prestígio diferidos, resultantes da sua tradição e qualificação no mercado e da qualidade e confiança que inspira, vinculadas, essencialmente, à boa imagem dos produtos ou serviços a que se aplica, exercendo um acentuado magnetismo, uma extraordinária força atrativa sobre o público em geral, indistintamente, elevando-se sobre os diferentes mercados e transcendendo a função a que se prestava primitivamente, projetando-se apta a atrair clientela pela sua simples presença."
\end{abstract}

A marca considerada de alto renome não poderá ser aplicada a nenhum outro produto ou serviço, qualquer que seja a classe, impedindo-se com isso que a reprodução por outra marca induza o consumidor em erro ou confusão. Nesse sentido, exponha-se uma situação exemplificativa: a empresa Unilever N.V., por já ter o alto renome de sua marca "CICA" declarado pelo INPI, desde 12/04/2005, detém proteção contra qualquer marca semelhante que venha a ser depositada para designar produtos diversos, tais como pneus, fraldas, persianas, etc., mesmo não atuando nestas áreas.

Tendo em vista que a LPI não traz critérios objetivos para a aferição do alto renome, o INPI instituiu alguns parâmetros na Resolução n 121 de 2005. Em seu art. 4을 apresenta-se um elenco de elementos informativos que poderão ajudar na comprovação do alto renome, conforme segue:

“1) data do início do uso da marca no Brasil;

2) público usuário ou potencial usuário dos produtos ou serviços a que a marca se aplica;

3) fração do público usuário ou potencial usuário dos produtos ou serviços a que a marca se aplica, essencialmente pela sua tradição e qualificação no mercado, mediante pesquisa de opinião ou de mercado ou por qualquer outro meio hábil;

4) fração do público usuário de outros segmentos de mercado que, imediata e espontaneamente, identifica a marca com os produtos ou serviços a que ela se aplica, mediante pesquisa de opinião ou de mercado ou por qualquer outro meio hábil;

5) fração do público usuário de outros segmentos de mercado que, imediata e espontaneamente, identifica a marca essencialmente pela sua tradição e qualificação no mercado, mediante pesquisa de opinião ou de mercado ou por qualquer outro meio hábil;

6) meios de comercialização da marca no Brasil;

7) amplitude geográfica da comercialização efetiva da marca no Brasil e, eventualmente, no exterior;

8) extensão temporal do uso efetivo da marca no mercado nacional e, eventualmente, no mercado internacional;

9) meios de divulgação da marca no Brasil e, eventualmente, no exterior;

10) extensão temporal da divulgação efetiva da marca no Brasil e, eventualmente, no exterior; 
11) valor investido pelo titular em publicidade/propaganda da marca na mídia brasileira nos últimos 3 (três) anos;

12) volume de vendas do produto ou a receita do serviço nos últimos 3 (três) anos;

13) valor econômico da marca no ativo patrimonial da empresa."

Atualmente, a grande dificuldade que se impõe diz respeito ao procedimento instituído para obtenção do alto renome. A citada Resolução $n^{\circ}$ 121 determina que a proteção especial do alto renome seja apenas requerida ao INPI, pela via incidental, como matéria de defesa, frente à existência de marca de terceiro que apresente conflito com a marca invocada.

A exigência de que a alegação de alto renome de uma marca seja admitida apenas como matéria de defesa vem sendo bastante questionada, pois é freqüente a existência de empresas que desejam o reconhecimento do alto renome de sua marca, mas não se deparam, naquele momento, com nenhuma marca que com ela conflite.

Enquanto o procedimento não é repensado, vias transversas têm sido adotadas para obtenção do alto renome. A solução que se encontrou no mercado foi contratar o depósito de marca semelhante por outro titular para que se defenda a marca anterior, alegando o alto renome em sede de oposição.

\section{CONCLUSÃO}

Após analisar a legislação de propriedade industrial brasileira e definir as principais características do regime de proteção marcária que se estabeleceu no país, a partir do século XIX, esta pesquisa cumpriu seu objetivo.

Diante de todo o exposto, pode-se concluir que o diploma legal atual de disciplina das marcas representa importantes avanços com relação ao sistema anterior, trazendo resposta às mudanças na realidade da prática mercantil.

A função da marca mudou ao longo dos anos, juntamente com sua concepção jurídica. A definição de marca foi alargada, da mesma forma que as hipóteses de não registrabilidade foram mais cuidadosamente reguladas pelo 
legislador, fazendo-se sempre presente o intuito de evitar, principalmente, condutas desleais.

O sistema de registro de marcas atualmente adotado, tendo o Instituto Nacional de Propriedade Industrial como responsável pelo exame das condições de registrabilidade e pela concessão de registro, parece cumprir seu papel diante das boas condições de contraditório que estabelece. No entanto, ainda há alguns questionamentos que se impõem para reflexão: primeiramente, a morosidade do processo administrativo, que hoje leva até cinco anos para atingir a fase final de concessão do registro; e, por sua vez, a existência de impedimentos para o reconhecimento de importantes circunstâncias fáticas, tais como o alto renome. Preocupações estas que se justificam diante do fato de que a marca representa, hoje, um importante valor econômico para seu titular, um verdadeiro ativo empresarial.

\section{REFERÊNCIAS}

BARBOSA, Denis Borges. Uma introdução à propriedade intelectual, vol. I. Rio de Janeiro: Lúmen Júris, 1997. . Licenças e Cessões na Propriedade Industrial. [Online] www.denisbarbosa.addr.com, acesso em 03/01/2007.

BASSO, Maristela. Propriedade intelectual na era pós-OMC. Porto Alegre: Livraria do Advogado, 2005.

BRASIL. INPI. Resolução $n^{\circ} 51$. Diretrizes Provisórias de Análise de Marcas, 1997.

CERQUEIRA, Gama. Tratado de propriedade industrial. vol. I. Rio de janeiro: Forense, 1956.

1956.

. Tratado de propriedade industrial. vol. II. Rio de janeiro: Forense,

COELHO, Fábio Ulhoa. Curso de direito comercial, vol. $1,8^{a}$ edição. São Paulo: Saraiva, 2004.

CORREA, José Antônio Faria. Revista da ABPI nº 17, jul/ago, 1995. 
DANNEMANN, Gert Egon e CABRAL, Felipe Fonteles. Marcas no Brasil. [Online]. www.dannemann.com.br, acesso em 15/10/2006.

DI BLASI, Gabriel et al. A propriedade industrial. Rio de Janeiro: Forense, 2002.

FRANCESCHELLI. Trattado de diritto industriale. vol. I. Milão: Giuffrè, 1973.

LOUREIRO, Luiz Guilherme de A. V. A lei de propriedade industrial comentada. São Paulo: Lejus, 1999.

MENDONÇA, Carvalho de. Tratado de direito comercial brasileiro, vol. V, parte I, 5. ed. Rio de Janeiro: Freitas Bastos, 1955.

MORO, Maitê Cecília Fabbri. Direito de marcas: abordagem das marcas notórias na Lei 9.279/1996 e nos acordos internacionais. São Paulo: Revista dos Tribunais, 2003.

PAES, Paulo Roberto Tavares. Propriedade Industrial: Lei $n^{\circ} 9.279$, de 14.05.1996. Rio de Janeiro: Forense, 2000.

PIMENTEL, Luiz Otávio. Propriedade intelectual e universidade: aspectos legais. Florianópolis: Fundação Boiteux, 2005.

Revista Brasileira de Direito Internacional, Curitiba, v.4, n.4, jul./dez.2006 